\begin{tabular}{|c|l|}
\hline Title & Synthesis of ZnO nanoflowers by solution plasma \\
\hline Author(s) & Saito, Genki; Hosokai, Sou; A kiyama, Tomohiro \\
\hline Citation & $\begin{array}{l}\text { Materials Chemistry and Physics, 130(1-2), 79-83 } \\
\text { https://doi.org/10.1016/.matchemphys.2011.05.084 }\end{array}$ \\
\hline Issue Date & 2011-10-17 \\
\hline Doc URL & http://hdl.handle.net/2115/47438 \\
\hline Type & article (author version) \\
\hline File Information & MCP130-1-2_79-83.pdf \\
\hline
\end{tabular}

Instructions for use 


\title{
Synthesis of ZnO Nanoflowers by Solution Plasma
}

\author{
Genki Saito, Sou Hosokai, *Tomohiro Akiyama
}

Center for Advanced Research of Energy and Materials,

Faculty of Engineering, Hokkaido University, Sapporo 060-8628, Japan

* Corresponding author: E-mail: takiyama@eng.hokudai.ac.jp, Phone: +81-11-706-6842, Fax: +81-11726-0731 


\begin{abstract}
We synthesized $\mathrm{ZnO}$ nanoflowers using a solution plasma. We examined the effects of the applied voltage and the concentration of the electrolyte on the morphology of the products. In the experiments, the zinc wire (cathode) was immersed in an electrolysis solution of $\mathrm{K}_{2} \mathrm{CO}_{3}$ (concentration: 0.01 to $5.00 \mathrm{M}$ ) and was electrically melted by a glow discharge at different voltages ranging from 42 to $200 \mathrm{~V}$. The results revealed that the products were nanoflowers having many nanorods (size: $<100 \mathrm{~nm}$ ). The $\mathrm{ZnO}$ nanoflowers had a wurtzite structure with the [0001] orientation in the growth direction. The product morphology changed with a change in the concentration of the electrolyte, $C$, and the applied voltage, $V$; that is, nanoflowers were generated under the limited conditions of $(C, V)=(1.0 \mathrm{M}, 66 \mathrm{~V}),(0.5 \mathrm{M}, 80 \mathrm{~V})$, and $(0.1 \mathrm{M}, 105 \mathrm{~V})$.
\end{abstract}

\title{
KEYWORDS:
}

Nano Crystals, Nanoparticles, Nano rods, Solution Plasma, Glow Discharge, Zinc Oxide, Flower-like, $\mathrm{ZnO}$ nanostructures 


\section{Introduction}

$\mathrm{ZnO}$, because of a wide band gap of $3.37 \mathrm{eV}$ and a high electron mobility $\left(100 \mathrm{~cm}^{2} \mathrm{~V}^{-1} \mathrm{~s}^{-1}\right)$, has drawn worldwide attention for its wide range of applications, such as optoelectronic nanodevices, dyesensitized solar cells, photocatalysts, sensors, biodevices, field-emission devices, piezoelectric transducers, varistors, ultraviolet (UV) and microwave absorbers, light-emitting diodes, surface acoustic devices (SAWs), polymer additives, ultraviolet nanolasers, and UV/visible photo-detectors, with unique properties of UV emission, optical transparency, electrical conductivity, piezoelectricity, and transparent conductivity at room temperature. Therefore, many researchers have reported on the fabrication of zinc oxide crystals by different methods, such as hydrothermal synthesis ${ }^{[[1-8]]}$, solution routes $^{[[9-22]]}$, ultrasonic irradiation ${ }^{[[1]]}$, microwave irradiation ${ }^{[[23,24]]}$, vapor-liquid-solid (VLS) growth $[[2,3]]$, pulsed laser ablation ${ }^{[[4]]}$, electrodeposition ${ }^{[[5]]}$, solvothermal method ${ }^{[[29,30]]}$, microemulsion ${ }^{[6]]}$ and thermal evaporation ${ }^{[[32,33]]}$. Further, various unique shapes of $\mathrm{ZnO}$ have been synthesized in the past decades, such as rods ${ }^{[[13,17,19,24,25,28,29,34]]}$, wires ${ }^{[[24-26]]}$, needles ${ }^{[[9,20]]}$, tetrapods ${ }^{[[7]]}$, tubes ${ }^{[[8]]}$, spheres ${ }^{[[3,21,24]]}$, hollow spheres ${ }^{[[1]]}$, stars ${ }^{[[9]]}$, ferns ${ }^{[[10]]}$, brushes ${ }^{[[11]]}$, layers ${ }^{[[8]]}$, disks ${ }^{[[24,28]]}$, nuts ${ }^{[[9]]}$, UFOs ${ }^{[[9]]}$, candles ${ }^{[[9]]}$, and flowers ${ }^{[[1,2,4,6-11,13-16,20,23,24,27,28,30,35]]}$.

Products having the abovementioned unique shapes are strongly expected to have more potential applications such as gas sensors using $\mathrm{ZnO}$ nanorods ${ }^{[[17,26]]}$ and photocatalysts of $\mathrm{Ag} / \mathrm{ZnO}$ with a heterostructure ${ }^{[[12]]}$. The three-dimensional, complex structures of $\mathrm{ZnO}$, such as stars, dendrites, and flowers, have recently drawn increased attention because of their unique properties. In particular, $\mathrm{ZnO}$ nanoflowers exhibit a high photocatalytic activity ${ }^{[[13]]}$ and have a large dielectric constant ${ }^{[[14]]}$.

Recently, plasma-assisted techniques based on the electrical discharge in a liquid have become a focus of many studies for the synthesis of nanoparticles ${ }^{[15-19]}$. The solution plasma causes a supercritical state of water in which the surface of the cathode is partially heated by a glow discharge at a high temperature $^{[[18]]}$. The solution plasma offers many advantages: (1) simple experimental setup, (2) no need to supply gas, (3) easy mass production, and (4) use of easy- available zinc wire as a raw material 
of nanoparticles. The solution plasma seems to be considerably attractive for the synthesis of $\mathrm{ZnO}$ nanocrystals from not only a scientific point of view but also an engineering one. However, to the best of our knowledge, few papers have been published on the $\mathrm{ZnO}$ production using the solution plasma. Therefore, we have studied the production of $\mathrm{ZnO}$ nanocrystals from a $\mathrm{Zn}$ wire (cathode) by using solution plasma; further, the effects of the applied voltage and the concentration of electrolysis solution on the morphology of the products in the solution plasma were mainly examined. The products recovered were characterized by using a field-emission electron microscope (FE-SEM), a transmission electron microscope (TEM), and selected area electron diffraction (SAED) patterns. The mechanisms of nanoparticles formation have also been discussed on the basis of the results. 


\section{Experimental}

\section{Experimental Setup}

Figure 1 shows the experimental apparatus used for the electrolysis experiments under stable power supply conditions (ZX800H, Takasago, Tokyo, Japan). A platinum wire of length $1000 \mathrm{~mm}$, diameter $0.5 \mathrm{~mm}$, and purity 99.98 mass\% (Nilaco, Tokyo, Japan) was used as the anode; this wire was bent into a half-round mesh and fixed in a glass frame. A zinc wire of diameter $1.0 \mathrm{~mm}$ and purity $99.99 \mathrm{mass} \%$ (Nilaco, Tokyo, Japan) was used as the cathode. It was shielded by an electrically insulated polytetrafluoroethylene (PTFE, TX-1, Sanplatec, Osaka, Japan) tube in order to obtain an exposed length of $10 \mathrm{~mm}$; the exposed part functioned as the net actual electrode. The distance between the electrodes was kept at $30 \mathrm{~mm}$. The electrolytes were solution of $\mathrm{K}_{2} \mathrm{CO}_{3}$ with $99.5 \%$ in purity (Kishida Chemical, Osaka, Japan) having concentrations ranging from 5.0 to $0.01 \mathrm{kmol} \cdot \mathrm{m}^{-3}$. The solution temperature at a depth of $10 \mathrm{~mm}$ was recorded every $5 \mathrm{~s}$ by using a polymer-coated thermistor thermometer (Ondotori TR-71Ui, T\&D, Nagano, Japan).

\section{Experimental Procedure and Characterizations}

The experimentals for producing nanoparticles were performed as a following procedure. First, the anode and cathode wire were washed by deionized water and ethanol by using an ultrasonic washer. Secondary, the voltage was applied at a rate of $0.5 \mathrm{~V} / \mathrm{s}$ until the formation of plasma under the constantvoltage control. Then, the voltage was fixed at a constant value for $1 \mathrm{~h}$. After the experiments, products were collected by the centrifugation and washed with deionized water. FE-SEM images of the products were taken by using a JEOL JSM-7400F (JEOL, Tokyo, Japan) microscope. The samples for observation were prepared by the deposition of the particle-dispersed droplets on a carbon tape. Transmission electron microscope (TEM) images and selected area electron diffraction (SAED) patterns 
were also taken by using a JEOL JEM-2010 (JEOL, Tokyo, Japan) microscope at an operating voltage of $200 \mathrm{kV}$. The water containing nanoparticles was dropped on a collodion-coated $\mathrm{Cu}$ microgrid (150 mesh, Nisshin EM, Tokyo, Japan) to observe by TEM. 


\section{Results and Discussion}

\section{Formation of nanoparticles during solution plasma}

The formation mechanism of the solution plasma is schematically illustrated in Fig.2 (a). A kind of electrolysis of water is performed. The current is increased with increasing the voltage when the voltage is low. Since the IR-loss is concentrated at the cathode/solution interface, the solution near the cathode is heated to the boiling point and a gas-layer containing hydrogen gas and steam was generated. Once the gas-layer is generated at the surface of the cathode, the current cannot increase any more thereafter and decreases because the cathode electrode and the solution do not touch each other (breakdown). If the voltage is sufficiently high, a glow discharge with intense light emission starts in the gas-layer. The electrons in the plasma layer are accelerated under a high electric field and impact a neutral atom to excite it. This excited atoms drop down immediately to a stable energy level by emitting light. The surface of the electrode partially melts to produce nanoparticles owing to the concentration of current causes by the electrothermal instability ${ }^{[20,21]}$. Figure 2 (b) shows the concentration mechanism of current. If the temperature at a certain point is larger than that in the surrounding area, the conductivity of plasma becomes high. The current increases due to the high conductivity of the plasma. The spot, where the current concentration occurs, is heated exclusively. Eventually, the cathode melts or ionizes at the spot to form nanoparticles ${ }^{[18]}$. 


\section{Effect of voltage and concentration of electrolysis solution}

Table I shows the experimental parameters and the corresponding morphology of the products, which were evaluated by SEM images as shown in Fig.3, at different solution concentrations ranging from 5.0 to $0.01 \mathrm{M}$. The voltages of plasma formation were increased with decreasing the concentration of electrolyte owing to the low electro-conductivity of the solution; the voltage was $50 \mathrm{~V}$ with the concentration of $2.0 \mathrm{M}$, and it was $190 \mathrm{~V}$ with the concentration of $0.01 \mathrm{M}$. This tendency agreed with the reported data ${ }^{[19]}$. Here, the voltages of plasma formation have a margin of error because the voltages of plasma formation were determined by the observation of the cathode. The maintained voltages were selected in order to keep glow discharge. The voltage was changed to investigate the effect of voltage at the concentration of $1.0 \mathrm{M}$ and $0.01 \mathrm{M}$. When gas-layer was generated at the surface of the cathode, the breakdown occurred because the current cannot increase any more. Thus, the power of breakdown was higher than the maintained power. With increasing the concentration of the solution, the maintained power decreased, and interestingly, the morphology of the products changed by the maintained power; no product less than $30 \mathrm{~W}$, nanoflowers in the range from 44 to $48 \mathrm{~W}$ and coarse particles more than 66 W. We observed light emission when the maintained powers were more than $44 \mathrm{~W}$. With more than 66 $\mathrm{W}$, the light emission became strong. These results suggested that the input voltage was not sufficient for producing particles in the case of under $30 \mathrm{~W}$. At an electric power of more than $66 \mathrm{~W}$, the cathode melted and generated coarse particles because of overheating. 


\section{Characterizations}

Figure 3 shows the SEM images of the products. Nanoflowers generated in the range of 44 to $48 \mathrm{~W}$, having many nanorods with a diameter of less than $100 \mathrm{~nm}$. With an increase in the concentration of the solution, the flowers were smaller: that is, $0.5-1.0 \mu \mathrm{m}$ in diameter at $1.0 \mathrm{M}$ (see Fig. 3(a)), 0.5-3.0 $\mu \mathrm{m}$ in diameter at 0.5 M (see Fig. 3(b)), and 0.5-5.0 $\mu \mathrm{m}$ in diameter at 0.1 M (see Fig. 3(c)). In contrast, an electric power of over $66 \mathrm{~W}$ generated coarse and agglomerated particles with the diameter of over 1 $\mu \mathrm{m}$. Figure 4(a) shows a typical TEM image of the $\mathrm{ZnO}$ nanoflowers, the inset of which is an SAED pattern taken from one of the nanorods. This confirmed the single crystal of the $\mathrm{ZnO}$ grown along the [0001] direction. Further, an HR-TEM image, shown in Figure 4(b), revealed a lattice fringe of approximately $0.52 \mathrm{~nm}$, which corresponded to the (0001) plane of the wurtzite $\mathrm{ZnO}$. 


\section{Formation mechanism of ZnO Nanoflowers}

Previously, the solution plasma had produced spherical nanoparticles as following steps; first, the surface of the cathode melted. Secondary, the molten metal formed sphere due to the surface tension in the solution, and then was solidified to synthesis of spherical nanoparticles ${ }^{[15,18,19]}$. However, the flower-like products formed due to another mechanism, which was not solidification after melting but nucleation and crystal growth. The flower-like structures have been produced through a hydrothermal synthesis ${ }^{[11-8]]}$ and solution routes ${ }^{[[9-22]]}$. The growth units of $\mathrm{ZnO}$ nanoflowers in these methods are a $\left[\mathrm{Zn}\left(\mathrm{NH}_{3}\right)_{4}\right]^{2+}$ or $\left[\mathrm{Zn}(\mathrm{OH})_{4}\right]^{2-}$ ions. The $\left[\mathrm{Zn}\left(\mathrm{NH}_{3}\right)_{4}\right]^{2+}$ ion were synthesized by a reaction between an ammonia water and a zinc salt such as $\mathrm{ZnCl}_{2}, \mathrm{ZnSO}_{4}$ and $\mathrm{Zn}\left(\mathrm{NO}_{3}\right)_{2}$. The $\left[\mathrm{Zn}(\mathrm{OH})_{4}\right]^{2-}$ ions can be formed by a reaction between an alkaline solution, which formed $(\mathrm{OH})^{-}$ion such as $\mathrm{NaOH}$, and a zinc salt. Considering our experimental conditions, the precursor of our $\mathrm{ZnO}$ nanoflowers was the $\left[\mathrm{Zn}(\mathrm{OH})_{4}\right]^{2-}$ ions. The possible formation mechanism of the $\mathrm{ZnO}$ nanoflowers was discussed on the basis of the experimental data as follows. First, $\left[\mathrm{Zn}(\mathrm{OH})_{4}\right]^{2-}$ ions were formed around the electrode; the surface of the $\mathrm{Zn}$ electrode formed $\mathrm{ZnO}$ by the steam corrosion at a high temperature, as shown in equation (1) and the product $\mathrm{ZnO}$ reacted with the hydroxide ions and water to produce the $\left[\mathrm{Zn}(\mathrm{OH})_{4}\right]^{2-}$ ions $[$ see equation (2)]. Secondary, $\left[\mathrm{Zn}(\mathrm{OH})_{4}\right]^{2-}$ ions transferred from the electrode surface to the area of low temperature. Then, solid $\mathrm{ZnO}$ crystallized with a decrease in temperature via reaction (3). According to the thermodynamic calculation of reaction (3), the reaction easily proceeds at a low temperature.

$$
\begin{array}{lll}
\mathrm{H}_{2} \mathrm{O}+\mathrm{Zn}(\mathrm{s}) & \rightarrow & \mathrm{ZnO}(\mathrm{s})+\mathrm{H}_{2}(\mathrm{~g}) \\
\mathrm{ZnO}(\mathrm{s})+\mathrm{H}_{2} \mathrm{O}+2 \mathrm{OH}^{-} & \rightarrow & {\left[\mathrm{Zn}(\mathrm{OH})_{4}\right]^{2-}} \\
{\left[\mathrm{Zn}(\mathrm{OH})_{4}\right]^{2-}} & \rightarrow & \mathrm{ZnO}+\mathrm{H}_{2} \mathrm{O}+2 \mathrm{OH}^{-}
\end{array}
$$


Because of the high growth rate along the [0001] direction $[[24,28,35]], \mathrm{ZnO}$ crystals grew preferentially along the [0001] direction to form many nanorods. In contrast, with an increase in the electric power, the electrode temperature became sufficiently high to melt the cathode (melting point of $\mathrm{Zn}=692.68 \mathrm{~K}$ ); the electrode melting resulted in coarse particles. The abovementioned discussions on the possible formation mechanism of the products are summarized in Figure 5. 


\section{Conclusions}

In this paper, the synthesis of $\mathrm{ZnO}$ nanocrystals using a solution plasma was studied. In the experiments, we applied an electric voltage from 42 to $200 \mathrm{~V}$ to the electrodes of both $\mathrm{Zn}$ and platinum in a $\mathrm{K}_{2} \mathrm{CO}_{3}$ solution with different concentrations ranging from 0.01 to $5.00 \mathrm{M}$, and observed the products by using a SEM and TEM. The following conclusions were derived:

1. A high voltage was required to maintain the plasma near the $\mathrm{Zn}$ electrode at a low electrolyte concentration. The SEM and TEM observations demonstrated that the product morphology depended strongly on the concentration, $\mathrm{C}$, and the voltage, $\mathrm{V}$; that is, no product was obtained when $(C, V)=(\geqq 1.0 \mathrm{M}, \leqq 60 \mathrm{~V})$, nanoflowers when $(\mathrm{C}, \mathrm{V})=(1.0 \mathrm{M}, 66 \mathrm{~V}),(0.5 \mathrm{M}, 80 \mathrm{~V})$, $(0.1 \mathrm{M}, 105 \mathrm{~V})$, and coarse particles when $(\mathrm{C}, \mathrm{V})=(\leqq 0.1 \mathrm{M}, \geqq 110 \mathrm{~V})$.

2. According to the SEM, TEM, and SAED patterns, the nanoflowers consisted of many nanorods (size: $<100 \mathrm{~nm}$ ) and exhibited a wurtzite structure of $\mathrm{ZnO}$ and a [0001] orientation in the growth direction.

3. The synthesis route of $\mathrm{ZnO}$ nanoflowers was explained by the precipitation of the $\mathrm{Zn}(\mathrm{OH})_{4}{ }^{2-}$ ions.

The results will also offer many benefits for producing nanoflowers of various oxides from precursor using simple equipment and production of $\mathrm{ZnO}$ in easily and quickly. 


\section{References}

[1] X. Wang, P. Hu, Y. Fangli, L. Yu, J. Phys. Chem. C, 111 (2007) 6706-6712.

[2] P.X. Gao, Z.L. Wang, J. Phys. Chem. B, 108 (2004) 7534-7537.

[3] R.K. Joshi, Q. Hu, F. Alvi, N. Joshi, A. Kumar, J. Phys. Chem. C, 113 (2009) 16199-16202.

[4] Y. Ishikawa, Y. Shimizu, T. Sasaki, N. Koshizaki, J. Colloid Interface Sci., 300 (2006) 612-615.

[5] F. Xu, Y. Lu, Y. Xie, Y. Liu, Materials \& Design, 30 (2009) 1704-1711.

[6] X. Li, G. He, G. Xiao, H. Liu, M. Wang, J. Colloid Interface Sci., 333 (2009) 465-473.

[7] M.N. Jung, S.H. Park, S.Y. Ha, S.J. Oh, Y.R. Cho, J.S. Park, I.H. Im, B.H. Koo, T. Yao, J.H. Chang, Physica E: Low-dimensional Systems and Nanostructures, 40 (2008) 2761-2764.

[8] L. Lin, H. Watanabe, M. Fuji, M. Takahashi, Adv. Powder Technol., 20 (2009) 185-189.

[9] S. Cho, S.-H. Jung, K.-H. Lee, J. Phys. Chem. C, 112 (2008) 12769-12776.

[10] X. Li, F. Zhao, J. Fu, X. Yang, J. Wang, C. Liang, M. Wu, Crystal Growth \& Design, 9 (2008) 409413.

[11] Y. Zhang, J. Xu, Q. Xiang, H. Li, Q. Pan, P. Xu, J. Phys. Chem. C, 113 (2009) 3430-3435.

[12] Y. Zheng, L. Zheng, Y. Zhan, X. Lin, Q. Zheng, K. Wei, Inorg. Chem., 46 (2007) 6980-6986.

[13] Y. Wang, X. Li, N. Wang, X. Quan, Y. Chen, Sep. Purif. Technol., 62 (2008) 727-732.

[14] M.K. Gupta, N. Sinha, B.K. Singh, N. Singh, K. Kumar, B. Kumar, Mater. Lett., 63 (2009) 19101913.

[15] K. Azumi, A. Kanada, M. Kawaguchi, M. Seo, Hyomen gijutsu, 56 (2005) 938-941.

[16] N. Tarasenko, A. Nevar, M. Nedelko, physica status solidi (a), 207 (2010) 2319-2322.

[17] V. Burakov, A. Nevar, M. Nedel'ko, N. Tarasenko, Technical Physics Letters, 34 (2008) 679-681.

[18] Y. Toriyabe, S. Watanabe, S. Yatsu, T. Shibayama, T. Mizuno, Appl. Phys. Lett., 91 (2007) 041501-041503.

[19] G. Saito, S. Hosokai, T. Akiyama, S. Yoshida, S. Yatsu, S. Watanabe, J. Phys. Soc. Jpn., 79 (2010) 083501.

[20] K. Okazaki, Y. Mori, K. Hijikata, K. Ohtake, AIAA Journal, 16 (1978) 334-339.

[21] R. Uncles, A. Nelson, Plasma Physics, 12 (1970) 917. 


\section{Figure captions}

Figure 1. Schematic representation of the experimental apparatus of plasma electrolysis for the synthesis of Zn nanoparticles.

Figure 2. (a) Formation mechanism of nanoparticles during solution plasma. (b) Concentration mechanism of current. If the temperature at a certain point is larger than in the surrounding area, the conductivity of plasma becomes high. The current increased induced by the high conductivity. The spot of current concentration was heated extra. Eventually, the cathode melted and formed nanoparticles.

Figure 3. SEM images of products obtained under different conditions of $\mathrm{K}_{2} \mathrm{CO}_{3}$ concentration and charged electric voltage. High $\mathrm{K}_{2} \mathrm{CO}_{3}$ concentration and low electric voltage induced the production of $\mathrm{ZnO}$ nanoflowers.

Figure 4. (a) TEM image of a $\mathrm{ZnO}$ nanorod peeled from the $\mathrm{ZnO}$ nanoflower $\left(1.0-\mathrm{M} \mathrm{K}_{2} \mathrm{CO}_{3}, 66 \mathrm{~V} 44\right.$ W) and its corresponding SAED pattern. (b) High-resolution TEM image.

Figure 5. Images of $\mathrm{ZnO}$ synthesis via solution glow discharge. 
Table

Table I Experimental parameters and corresponding morphology of final products

\begin{tabular}{|c|c|c|c|c|c|}
\hline \multirow{2}{*}{$\begin{array}{c}\text { Concentratio } \\
n \\
/ \mathrm{kmol} \cdot \mathrm{m}^{-3}\end{array}$} & \multicolumn{2}{|c|}{ Voltage/V } & \multicolumn{2}{|c|}{ Power/W } & \multirow[b]{2}{*}{ Morphology } \\
\hline & $\begin{array}{c}\text { Plasma } \\
\text { Formation }\end{array}$ & $\begin{array}{c}\text { Maintaine } \\
d\end{array}$ & Breakdown & $\begin{array}{c}\text { Maintaine } \\
d\end{array}$ & \\
\hline 5.00 & - & 42 & - & 29 & No product \\
\hline 2.00 & 50 & 50 & 52 & 28 & No product \\
\hline 1.00 & 54 & 60 & 97 & 30 & No product \\
\hline 1.00 & 48 & 66 & 98 & 44 & Nanoflowers \\
\hline 0.50 & 75 & 80 & 160 & 48 & Nanoflowers \\
\hline 0.10 & 89 & 105 & 112 & 47 & Nanoflowers \\
\hline 0.10 & 84 & 110 & 103 & 66 & Coarse particles \\
\hline 0.01 & 190 & 200 & 245 & 168 & Coarse particles \\
\hline
\end{tabular}




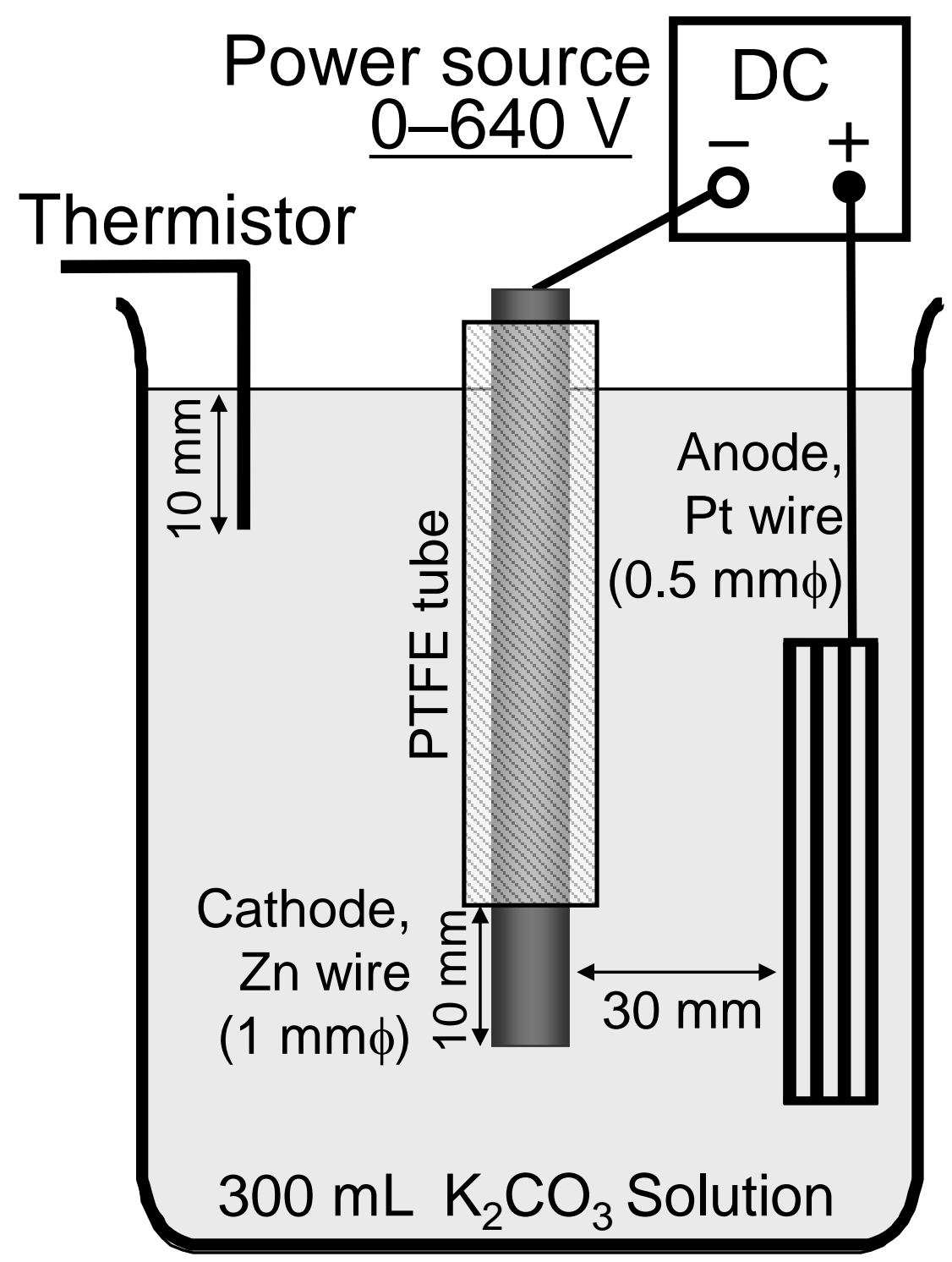


(a) Electrolysis of water

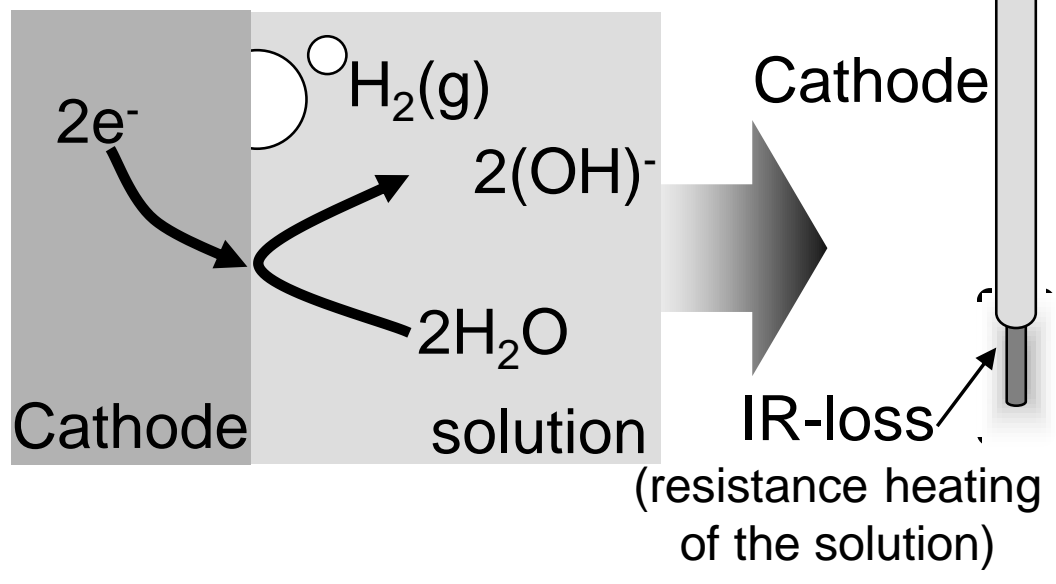

Plasma-sheath
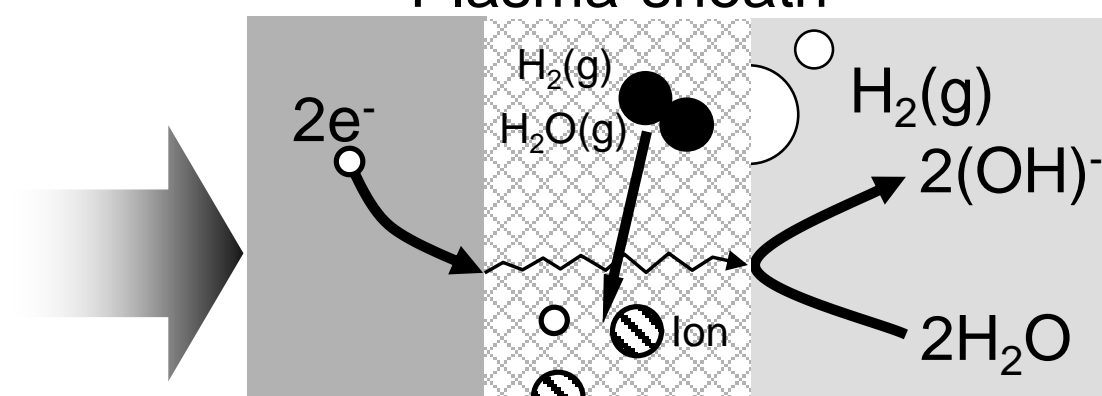

Cathode $\theta_{\text {oflectron solution }}$
Anode

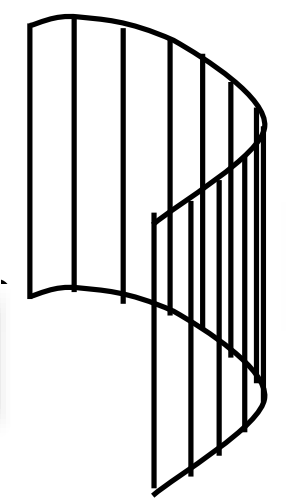

Gas-layer

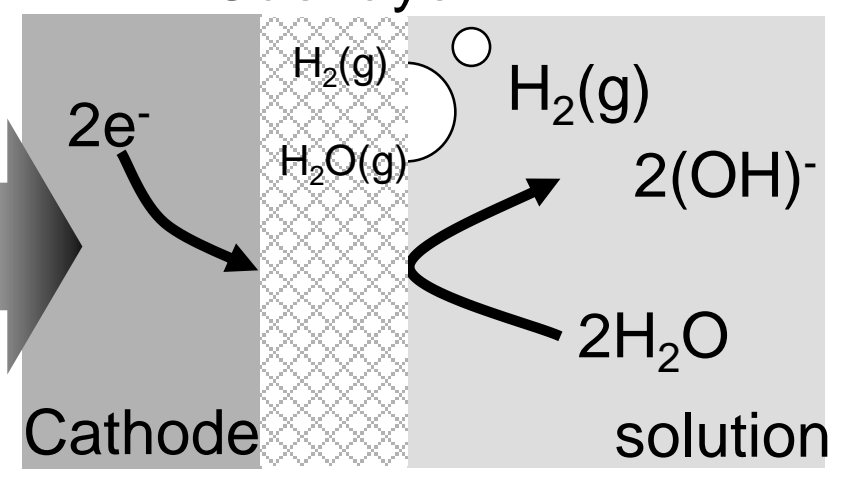

Concentration of Current

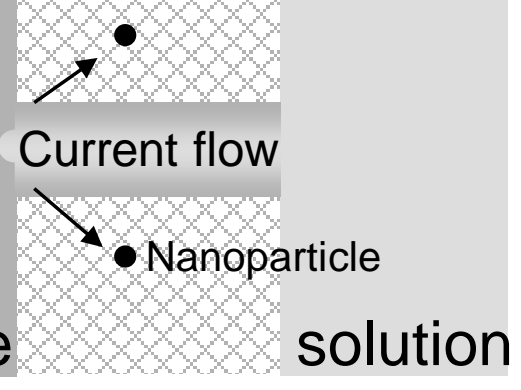

Cathode

solution

(b)

$\uparrow$ Temperature

$\uparrow$ Conductivity

$\uparrow$ Current

$\uparrow$ Joule heating t

Electrode melting \& nanoparticles formation 
(a) $1.0 \mathrm{M} \mathrm{K}_{2} \mathrm{CO}_{3}, 66 \mathrm{~V} 44 \mathrm{~W}$

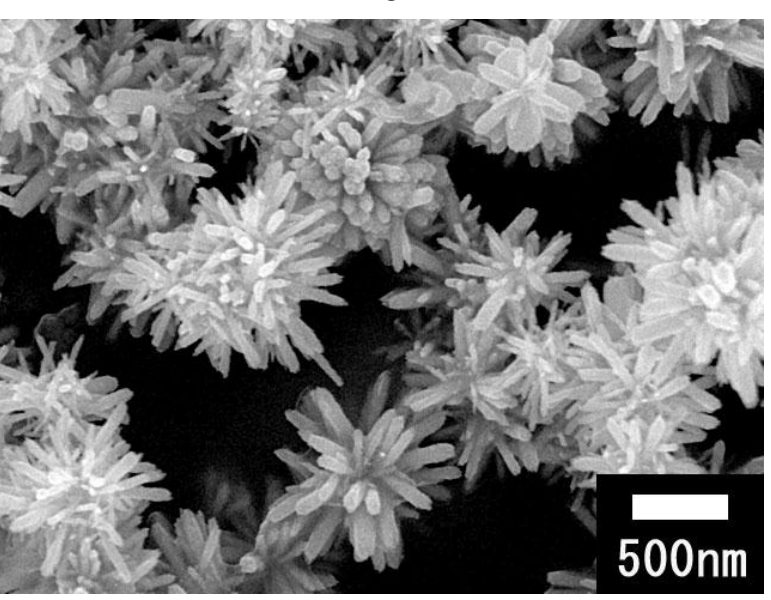

(d) $0.1 \mathrm{M} \mathrm{K}_{2} \mathrm{CO}_{3}, 110 \mathrm{~V} 66 \mathrm{~W}$

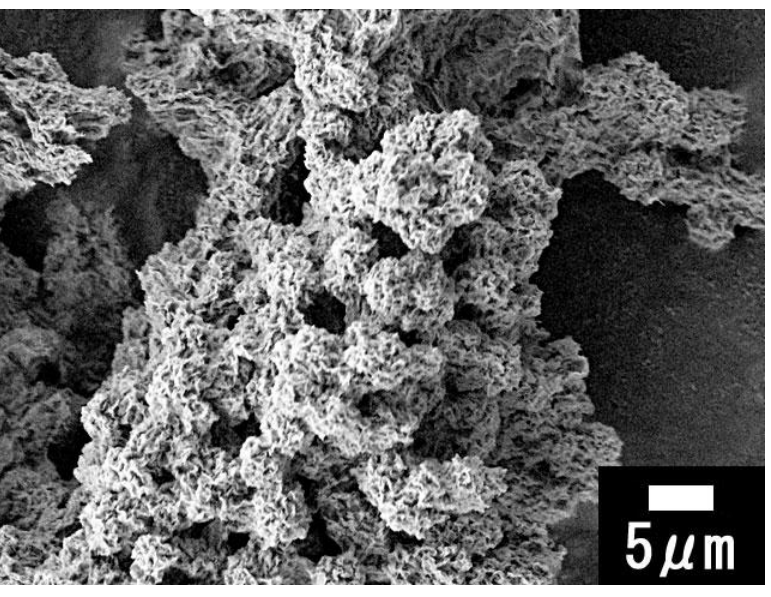

(b) $0.5 \mathrm{M} \mathrm{K}_{2} \mathrm{CO}_{3}, 80 \mathrm{~V} 48 \mathrm{~W}$

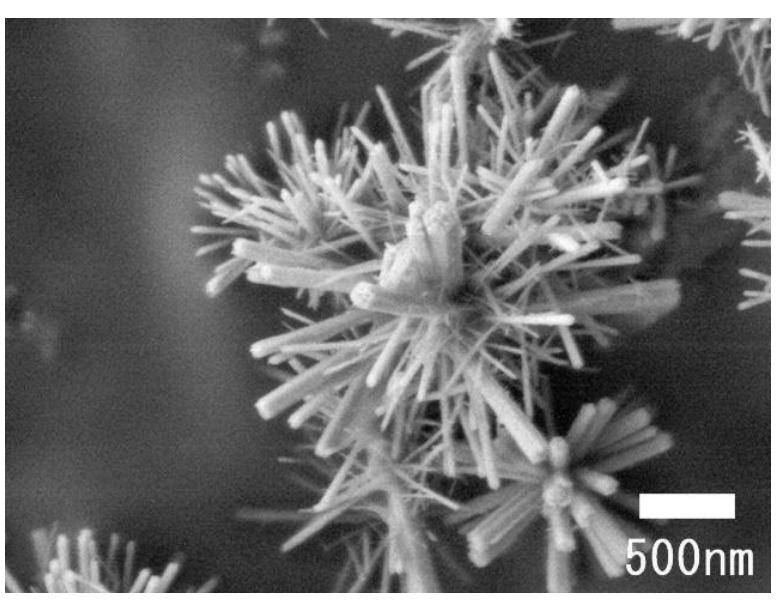

(c) $0.1 \mathrm{M} \mathrm{K}_{2} \mathrm{CO}_{3}, 105 \mathrm{~V} 47 \mathrm{~W}$

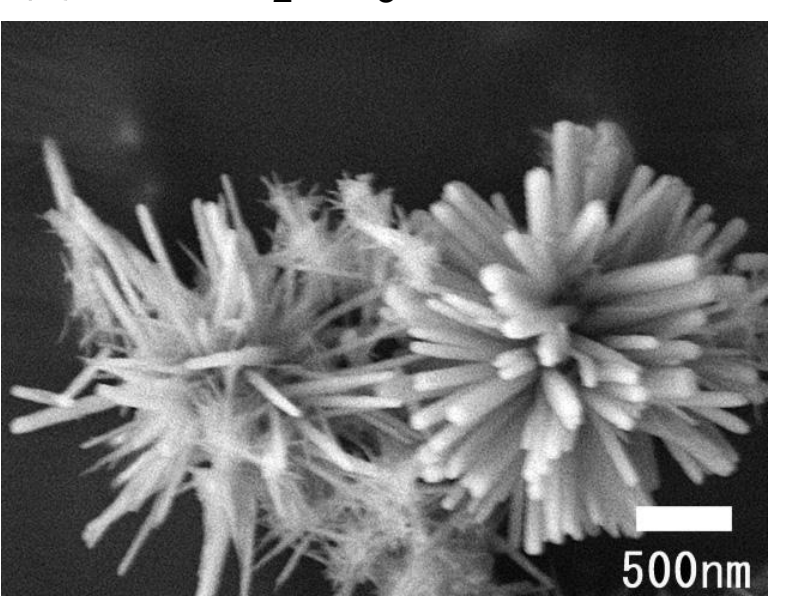

(e) $0.01 \mathrm{M} \mathrm{K}_{2} \mathrm{CO}_{3}, 200 \mathrm{~V} 168 \mathrm{~W}$

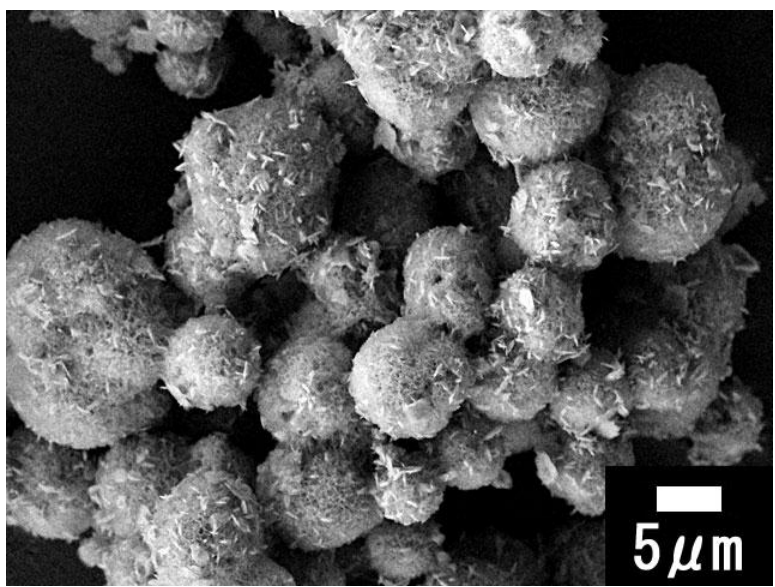




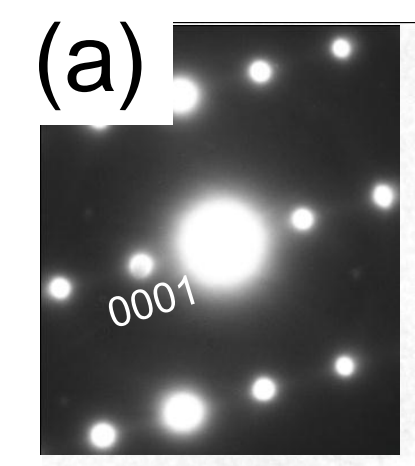

(b)

$100 \mathrm{~nm}$ 

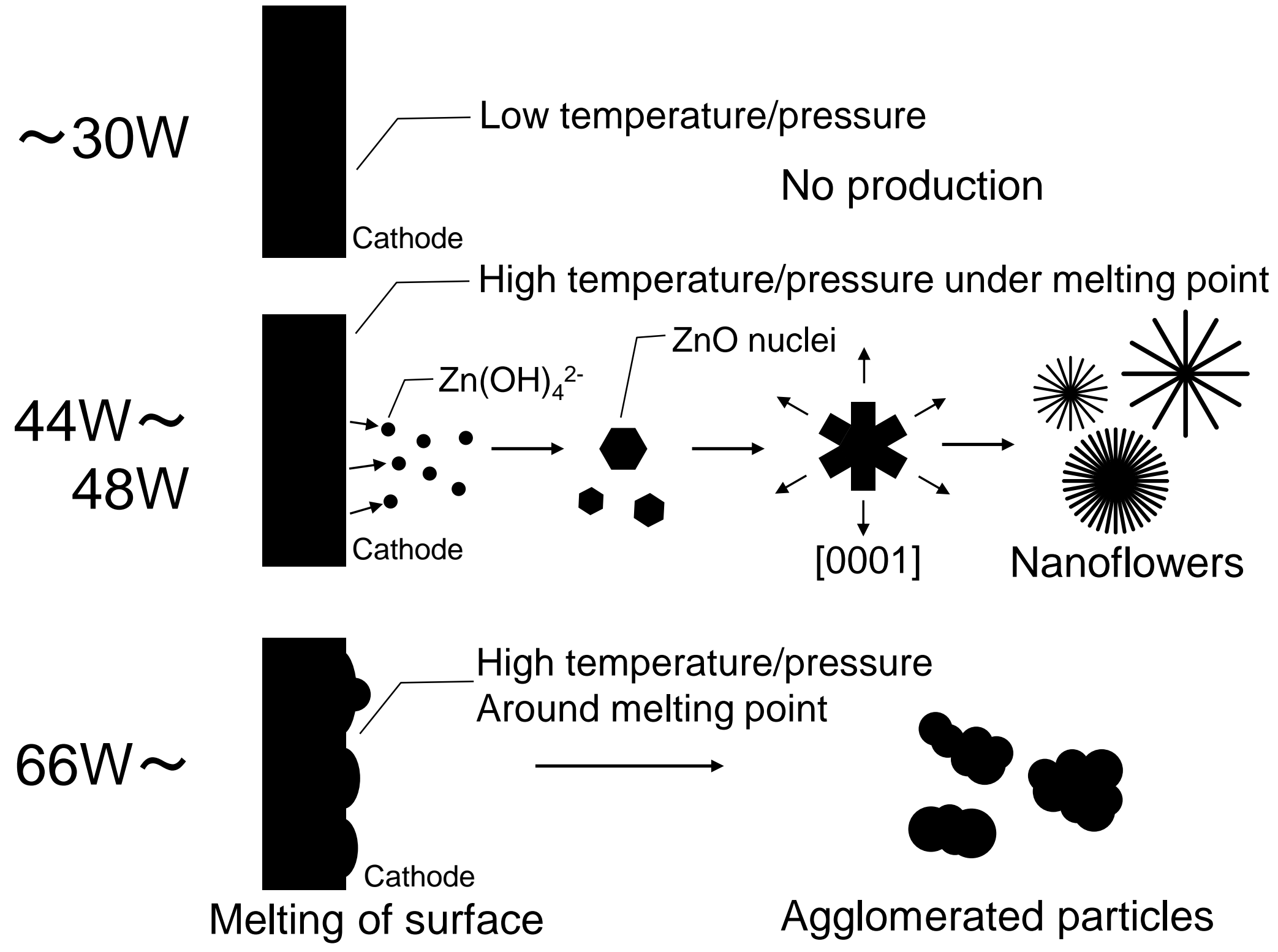


\begin{tabular}{|c|c|c|c|c|c|}
\hline \multirow{2}{*}{$\begin{array}{c}\text { Concentration } \\
\quad / \mathrm{kmol} \cdot \mathrm{m}^{-3}\end{array}$} & \multicolumn{2}{|c|}{ Voltage/V } & \multicolumn{2}{|c|}{ Power $/ W$} & \multirow[b]{2}{*}{ Morphology } \\
\hline & $\begin{array}{c}\text { Plasma } \\
\text { Formation }\end{array}$ & Maintained & Breakdown & Maintained & \\
\hline 5.00 & - & 42 & - & 29 & No product \\
\hline 2.00 & 50 & 50 & 52 & 28 & No product \\
\hline 1.00 & 54 & 60 & 97 & 30 & No product \\
\hline 1.00 & 48 & 66 & 98 & 44 & Nanoflowers \\
\hline 0.50 & 75 & 80 & 160 & 48 & Nanoflowers \\
\hline 0.10 & 89 & 105 & 112 & 47 & Nanoflowers \\
\hline 0.10 & 84 & 110 & 103 & 66 & Coarse particles \\
\hline 0.01 & 190 & 200 & 245 & 168 & Coarse particles \\
\hline
\end{tabular}

